\title{
Values as a Driver for Capacity Development: Promoting Justice in Papua New Guinea
}

\author{
Frazer Pitpit and Heather Baser
}

\begin{abstract}
This case study shows how the Office of the Public Solicitor of Papua New Guinea developed a social change vision built on clearly articulated values and used this as a driver for enhancing both its legitimacy and its capacity more generally. The experience was monitored using the capacity development framework developed by the European Centre for Development Policy and Management. This emphasises individual empowerment and engagement as well as skills, and how these are articulated with collective capabilities in particular contexts to build a system's capacity to perform. The authors suggest that evolution of systemic capacity is a process that requires drivers beyond organisational self interest, personal advantage or greater efficiency. The experience of the OPS shows that capacity can emerge out of fruitful relationships among people holding common ideals who want to make a difference, rather than just resulting from improvements to technique, structure or assets.
\end{abstract}

\begin{abstract}
1 Introduction
No-one would deny that Papua New Guinea (PNG) has a law and justice problem. Port Moresby is making progress in strengthening some of the organisations that make up the criminal justice system so that they can more effectively address crime. This is the story of one of these - the Office of the Public Solicitor (OPS) - and how it has developed a social change vision built on clearly articulated values and used this as a driver for developing both its legitimacy and its capacity more generally.
\end{abstract}

\section{Background}

Prior to its independence in 1975, the territory of Papua and New Guinea was highly decentralised and districts were divided into sub-districts and administered by kiaps who patrolled widely. The kiap was responsible for policing, limited magisterial duties and the management of lockups in the local area of command. The Australian colonial administration did not, however, see kiap Justice as an appropriate option for the long term and began a transition to a centralised system of justice as early as the 1950s. The legal and judicial system chosen was a based on a centralised Western-style model with no attempt to integrate Papuan customary or indigenous systems.

The decision to establish such a system is seen by many observers as undermining local social controls and contributing to the subsequent growth of PNG's 'law and order' problems (Dinnen 2003: 4), including the revival of intergroup fighting in the central part of the country, the Highlands. The fact that the system was badly underfunded also contributed to low levels of performance. The Australian academic, Sinclair Dinnen, who specialises in the interface between formal and informal justice practices, suggests that the shortcomings of the system could be 'attributed as much to a lack of legitimacy and strong social foundations as to its patent lack of institutional capacity' (Dinnen 2004). Because the public service has for the most part fallen into dysfunctional work habits and cynicism, building integrity and professionalism is critical to restoring legitimacy. Much of the will to serve has disappeared and motivation to improve service delivery is limited. 
By the late 1990s, there was a growing feeling among some Papua New Guineans that there needed to be a mechanism to both encourage leadership to emerge in the law and justice sector and to improve the link between the allocation of resources and performance. This led to the articulation of a law and justice sector approach of agencies working together which was at the core of the National Law and Justice Policy and Plan of Action approved in 2001. This was then translated into the PNG Law and Justice Sector Strategic Framework (SSF) whose vision is: 'a just, safe and secure society for all people in PNG' (Law and Justice Sector 2006: 1).

Since the late 1980s, the Australian Government, through the Australian Agency for International Development (AusAID), has been supporting development activities with various organisations in the law and justice sector. As of 2004 and the beginning of the PNG Law and Justice Sector Program (LJSP), assistance has focused on supporting the government and civil society to plan, design, implement, monitor, evaluate and report on activities that implement the Strategic Framework. The second phase of this assistance began in April 2009 with the Papua New Guinea-Australia Law and Justice Sector Partnership (PALJP). Between increased budgetary allocations by the Government of PNG and the Australian support, the resources available for agencies in the law and justice sector have increased significantly over the past five years.

The whole approach and design of the LJSP and later the PALJP was about capacity development. In operational terms, this meant supporting Papua New Guineans to take responsibility for implementing the Strategic Framework and the various activities defined in it. The objective of the members of the LJSP/PALJP team was to help their counterparts, both individuals and organisations, to develop their own capacity.

Over the course of the first two or three years of the LJSP, it became obvious that the resultsbased management system used for monitoring project activities was not capturing adequately the capacity results of the programme. At that time (2007), there was little experience in the donor community with alternative systems. The European Centre for Development Policy Management was, however, just completing a study entitled Capacity, Change and Performance (Baser and Morgan 2008) on the nature of capacity and how to unpack it or break it down. The LJSP management then decided to invite three of the best performing organisations in the law and justice sector to be part of an experimental application of the framework for monitoring capacity coming out of the Capacity, Change and Performance study. This article is an adaptation of one of the resulting case studies which Heather Baser wrote on the basis of interviews with the Public Solicitor, his staff and various people who are in contact with the OPS (Baser 2009a,b). Much of the article is written in the first person - 'I', 'me', 'we' and 'ours' - to reflect the views of either the Public Solicitor, Mr Frazer Pitpit, or the management staff of the OPS more generally.

\section{History and values of the OPS}

The OPS was never well staffed but the World Bank public sector reform programme of the mid-1990s resulted in a reduction in the number of employees by a further $30-50$ per cent. By the 2000 s, the workforce was ageing and the OPS was increasingly unable to provide adequate service to the public. By November 2004, after a year in the position of Public Solicitor, I was very discouraged and 'ready to throw in the towel'. However, AusAID and the LJSP management agreed to provide support including: defining options for how PS services could be provided, looking at the operations and the organisation of the OPS, skills strengthening, an improved case management system and some support to address the backlog of cases. The OPS has made significant progress on all of these issues, to the point where it was chosen as the best performing organisation in the sector at the Annual Sectoral Awards Ceremony in December 2008.

The authors of this article suggest that a critical element of this success has been the clear articulation of values: 'the beliefs of a person or social group in which they have an emotional investment'. ' These values often provide meaning or even moral purpose to activities. From this perspective, for capacity to evolve, especially at the level of second order or transformational change, there needs to be more than improvements to technique, structure or assets. The process requires a contribution to a higher ideal or purpose, based on an answer to the 'why' of capacity development that goes 
beyond organisational self-interest, personal advantage or greater efficiency. This higher ideal in turn provides legitimacy (Baser and Morgan 2008: 56-7).

Our values in the OPS are rooted in principles expressed in three official government documents, these being mutually reinforcing:

- The Constitution of the Independent State of Papua New Guinea, which in the Preamble under the section on Equality and Participation calls for a social vision to include:

- 'an equal opportunity for every citizen to take part in the political, economic, social, religious and cultural life of the country';

- 'equal participation by women citizens in all political, economic, social and religious activities'; and

- 'equalisation of services in all parts of the country, and for every citizen to have equal access to legal processes and all services, governmental and otherwise, that are required for the fulfilment of his or her real needs and aspirations' (Office of the Legislative Council 1976).

The Constitution also assigns the Public Solicitor a specific role, i.e. 'to provide legal assistance to a person in need of help by him who has been charged with an offence punishable by imprisonment for more than two years'. This role as Public Defender entrusts the Public Solicitor with the role of removing 'the perception that there are two sets of laws: one for the common people, the other for the rich and the affluent or powerful' (Office of the Public Solicitor undated: 7).

- The Sector Strategic Framework which presents the vision of a just, safe and secure society for all (Law and Justice Sector 2006: 1);

- The Supreme Court's declaration in Supreme Court Reference no. 1, 1978 (OPS undated: 7) that the Public Solicitor's OPS is 'an institution of the people of $\mathrm{PNG}$, rather than an office of the state. As such, the OPS is the protector of people's rights and should be a testimonial symbol of democracy and of the rule of law.

Together, these three documents provide a vision for the OPS which has allowed us to define both broad goals for the organisation and specific objectives for individuals. But before turning to the details of this, let us look at how the study Capacity, Change and Performance breaks down the concept of capacity.

\section{The framework from Capacity, Change and Performance}

Most frameworks have some central characteristics around which the basic principles revolve. In terms of the conceptual framework from Capacity, Change and Performance, one of the most critical characteristics is empowerment and how it helps an individual, an organisation or a group to be self-aware, to grow, to diversify and to survive. This implies that people have to engage to take control of their behaviour. Another important characteristic of capacity is the creation of public value through positive social change. To operationalise these characteristics, actors involved in a development activity need certain skills or abilities, as follows:

- Individual competencies are the ability of individual human beings to do something and can include a range of skills and abilities from technical or logistical to mindsets, motivations and hopes. The most obvious contributions at the individual level were usually those of leaders at all levels.

- Collective capabilities are the day-to-day skills, attitudes and motivations of a group, an organisation or a system to do things and to sustain itself.

- Capacity development is the process of enhancing, improving and unleashing capacity. Capacity development is about how competencies and capabilities interrelate to encourage virtuous cycles that support broader capacity, for example and ideally, improved individual leadership reinforces the group's capability to build supportive networks and attract resources. This, in turn, increases overall capacity. This increased capacity opens up new opportunities for the organisation and the individuals within it. And the cycle continues.

- System capacity is the overall higher order ability of a system to perform and make a contribution. It is the outcome of the interrelationships among competencies, capabilities and the context, with the outcome being different from any one of the inputs. Aspects of such a 'capacitated' system would include legitimacy, relevance, resilience and sustainability. 


\section{Turning the vision into values}

In the OPS, we are trying to adapt the vision described above to the capacity framework. First, we have interpreted the vision and particularly the Supreme Court declaration that we are 'an institution of the People' as calling for certain individual competencies including skills, attitudes and mindsets. These include the motivation and skills to carry out professional tasks in a way that effectively serves the public. For example, a lawyer must meet regularly with clients, manage cases in a timely fashion and provide the best advice possible. Staff are required to keep regular hours, to be honest and to not accept payment for services which the law stipulates be provided gratis. Probity is particularly important in PNG where high levels of corruption have earned the country a rank of 151 out of 180 countries on the Transparency International Corruption Perceptions Index. This, together with inadequate services, has contributed significantly to undermining public confidence in government organisations.

We expect each staff member to adopt a moral stance of opposing social injustice not only for the clientele of the OPS but also more broadly in the community. This includes not only explaining to clients the direct details of their cases but also advising them of their legal rights. Outside the OPS, we want staff to be active citizens, to be part of their communities, to defend the rights of the disadvantaged in broader society and to oppose violence, gender inequality and discrimination against those with HIV/AIDS. This is a major commitment to the common good in a country where the collective sense of statehood is relatively underdeveloped and where values have traditionally been clan-based rather than nationwide.

Second, we have used the vision and particularly the goals of the Constitution to define what we need as collective capabilities to carry out our dayby-day functions. These include both internal and external capabilities. Internally, for example, we need a sense of group identity and purpose to meet the goals outlined in the Constitution and the management skills to ensure that staff actually carry out required functions. We need to encourage learning from each other and teamwork to develop policies and expand services. Externally, the team needs to build relationships with other government agencies and with the provinces to allow us to expand services beyond the capital and a few of the larger urban centres. Openness, exploration and piloting of new ideas and approaches are important to helping us adapt to the changing context. And finding a balance between centralising tendencies and the need to understand the needs of areas outside the capital is important.

Third, we have defined what we hope to achieve in terms of systems capacity. Legitimacy of the organisation will be seen in terms of the extent to which it is able to deliver on the Constitutional mandate, including providing effective and timely defence counsel in serious criminal cases and defending the human and civil rights of disadvantaged persons and minority groups nationwide. The transparency of processes is important and justice must not only be done but be seen to be done. 'The equal part of the quest for justice is maintaining the public confidence in the institutions that promote, protect and administer the rule of law in PNG (OPS undated: 7). The extent to which the organisation is seen to be resilient ${ }^{3}$ and relevant ${ }^{4}$ will also come into play.

\section{The processes used to reinforce values and vision in the OPS}

We have made a concerted effort in the OPS to inculcate the vision and values defined above in both individuals within the organisation and in organisational processes. First, we have taken steps to ensure that staff within the OPS respect the organisational ideals defined. This has meant releasing a number of employees who did not meet standards of probity, such as taking fees for services. It has also meant that in the re-staffing process resulting from a large increase in the number of employees in the OPS, a number of people who were not meeting professional norms previously did not qualify for new positions and were released. This included staff who were absent frequently or who were drinking on the job. This re-staffing process was transparent, fast and well documented. It was seen as an example of merit-based staff selection in a government where patronage has often trumped merit, resulting in negative effects on the quality of personnel. It was, however, not without some repercussions, such as threats against me as well as pressure from ethnic relationships. 


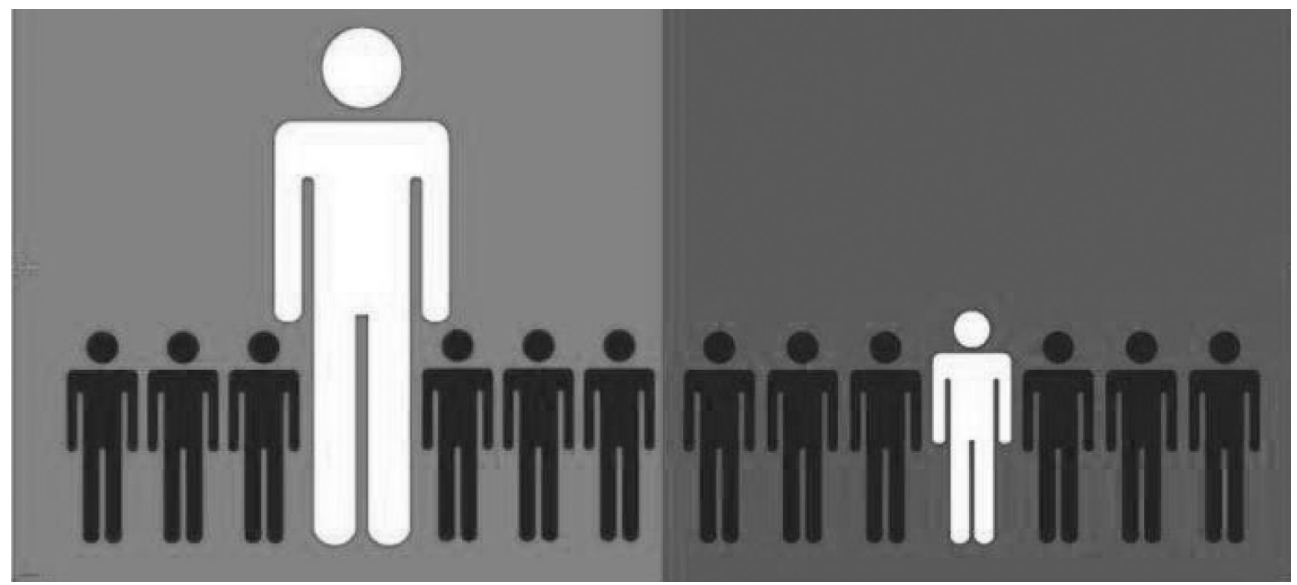

Second, we try to encourage staff to incorporate our values and vision into our everyday functions. This includes extensive training and mentoring on the norms of behaviour expected of staff and encouraging mutual respect and cooperation among staff. And in-keeping with the equality and participation theme of the Constitution, we are moving away from a centralised management model to one of a supportive boss ${ }^{5}$ where the hierarchical gap with staff is smaller and more decision-making is delegated down the line (Figure 1). This shift in management approach needs to be seen in the context of a public service where most staff expect the boss to take major decisions and are reluctant to take initiatives. It will take years to change such attitudes among older staff but there is more hope that the young hires in the OPS, two-thirds of whom are women, will adapt to new styles of management.

By putting several women into management positions, in a country where women have a low status in society, we have tried to promote the egalitarianism called for in the Constitution and challenge societal expectations that it is only men who act as leaders. These women have proven to be very effective in their roles and now serve as a role model for others.

Third, we have made some structural changes to help us to attain our vision. The goal of creating a more service oriented culture was, for example, the impetus for the OPS to seek and gain independence from the Department of Justice and Attorney General on which it had previously depended for budget allocations and operational support such as financial and personnel services.

Fourth, we are trying to put in place more effective structures for accountability. The OPS is, for example, publishing annual reports for the public and developing more detailed job descriptions so that staff will better understand their responsibilities and managers can hold them accountable. Managing the performance of staff is a challenging issue in a government which has not yet developed accountability and management systems that reflect national cultural norms while also incorporating international good practice. In a context where family and ethnic groups have primacy, managers find it difficult to apply impartial Western models of accountability.

\section{The influence of values on capacity}

Over the last five years, there have been major improvements in OPS competencies and capabilities, including better morale, faster service to clients and a broader range of activities. Although these and other improvements cannot be solely attributed to the inculcation of values and vision, staff of the OPS and the LJSP as well as with other stakeholders suggested a number of areas where the organisational ethic has had a positive influence.

In terms of individual competencies in the OPS, for example, the emphasis on integrity and professionalism has encouraged staff to adopt better work habits such as punctuality and a 
more professional appearance. They now treat their colleagues better and interact and share ideas and information in a way they did not do five years ago. Being part of an organisation with a broader purpose, in this case protecting the human rights of the accused, has raised morale and given staff a sense of self worth.

Building integrity and professionalism are particularly important in PNG because the public service in general has fallen into dysfunctional work habits and cynicism. Much of the will to serve has disappeared and motivation to improve service delivery is limited. Dealing with poor performance is thus an important step towards building a merit-based public service.

The articulation of values and moral purpose seems to have strengthened the collective capability of the organisation to commit and engage - to develop motivation and commitment and then to act. There is more group cohesion, more commitment to serving clients and more willingness to take on new tasks such as the development of paralegal offices in some areas not yet serviced by branch offices of OPS.

In terms of system capacity, the OPS has taken on a number of activities that increase its legitimacy in terms of defending human rights. These include class actions on behalf of aggrieved settlers, the establishment within the OPS of sections to service both the grade five and the juvenile courts, and membership on the Human Rights Committee which successfully pushed for the establishment of a Human Rights Commission.

Major increases in requests for legal assistance 875 per cent in the number of applications for criminal cases and 1,300 per cent in civil cases over the period of 2005 to $2008^{7}$ - suggest that the OPS awareness programme is increasing knowledge about the organisation among members of the public and that the organisation is seen as having increasing credibility. This success has been something of a double-edged sword, however, because it has created demand beyond what the OPS can handle. The result has been an increase in the number of cases classified as pending of 84 per cent in 2008.

In a country like PNG, where levels of fraud and corruption are high, building the legitimacy of the law and justice sector will depend in part on convincing the public that the employees of its various agencies are honest and trustworthy. This requires taking action when employees carry out illegal activities. Such action has been infrequent in the sector because of ethnic relationships and fear of retribution but OPS's actions in dismissing employees for accepting payment for services has sent a signal to other sector agencies.

\section{Conclusions}

We present our concluding thoughts from the point of view of each author in turn.

From the perspective of the OPS, we feel that we have made some important progress in developing our capacity as an organisation and that the values we have defined for ourselves have been important to this. They have helped to encourage us to tackle some issues which other law and justice agencies have not always been willing to address, such as dismissing nonperforming staff and embedding the merit principle in staffing processes. The progress made shows that capacity can develop out of fruitful relationships among actors with values who want to make a difference, rather than from technical fixes.

On the other hand, it is important not to exaggerate the progress we have made. There is a long history of neglect of public institutions in PNG and an accompanying high degree of demoralisation of staff to overcome. Many OPS staff are also young and inexperienced and even the older ones have usually not been adequately mentored to take on the roles the OPS requires of them. We will have to make concerted efforts for a long time before we can say our capacity is adequate to carry out our organisational mandate. In addition, we need to consolidate the new activities we have undertaken, reflect on what we have achieved and think about where we need to go in the future.

The figures we cite in this article on the number of applications for OPS support tell a story of increasing demand which is likely to continue. PNG is facing a major flood of many poorly educated young people with few prospects for employment coming into urban areas. The traditional village structures which have controlled social behaviour are less effective in 
the cities and have little influence on such young people, resulting in an upswell of crime.

Eighteen per cent of the male population of Port Moresby is estimated to live off the proceeds of crime (Blank 2008). The chances of this improving in the near future are slim.

What does this mean for the OPS? It means that we have to improve the quality of our staff through training, better management and mentoring and more empowerment. We have to be innovative in finding better ways of delivering services and to test them through experimenting, learning and adapting. We have to build our external networks of relationships to ensure that we have support when we need it, for example, when seeking increased budgetary resources. Continually developing our capacity like this will require both an understanding of what is happening in the sector and in the country more broadly and a strategic sense for how to respond to it. And all this, without forgetting our vision and values!

From the perspective of Ms Heather Baser, what does the case suggest about the application of the ECDPM framework?

Using the ECDPM methodology demands some new ways of thinking for those involved, for example, it asks people to think about what capacity is and how skills and motivations at different levels - the individual, the group interconnect and feed into system capacity. It also encourages them to think about intangibles such as leadership, motivation and relationships, as well as more traditional aspects of capacity such as budgets and facilities. In terms of capacity development, it asks for not only the story of what has happened but also an understanding of why things have rolled out in a certain way. In the OPS case, all this was challenging.

It was particularly challenging to distinguish between capabilities and overall system capacity. The capability to deliver legal aid services across the country tended to be seen as delivering the mandate of the organisation. But the mandate goes beyond specific tasks to encompass the relationship between the OPS and other government agencies, its resilience or ability to survive organisational crises such as changes in leadership, and its legitimacy with the public. If the OPS were seen to carry out its tasks in an inappropriate manner through, for example, regularly accepting fees for services which should be gratis, it would pay in terms of its legitimacy.

Adopting the whole capacity framework is likely to exceed the resources of virtually any organisation without some advance preparation. It requires understanding the underlying concepts but also developing internal capabilities to be able to apply them. Both take time and commitment. Any new system of monitoring also has to compete with existing ones which are all too often already seen as onerous. An organisation like OPS needs to think about the tradeoffs with existing reporting systems and the extent to which it wants to challenge these.

Should OPS decide to have a system for monitoring capacity, it needs to ask itself how far it should go and how fast. Monitoring the accomplishment of key capabilities with a focus on their contribution to organisational sustainability and resilience may be adequate in the short to medium term. In the longer term, however, understanding capacity and its development requires looking at how it evolves or emerges at the system level. Simplifying this process would make this task more appealing to organisations like OPS and one way of doing this would be to integrate the capacity framework into regular planning and reporting. This would allow activities to be defined in terms of the framework rather than appending a new way of thinking about capacity retroactively onto the activities over a five-year period, as was the case for the OPS.

And finally, we might well ask how this progress has been possible. Is it just values that have driven the process? In a complex environment like PNG, there is no one factor that accounts for all changes. In the case of the OPS, the leadership of the Public Solicitor was an important element. He provided vision in terms of ideals and activities and encouraged staff to learn from their experiences and to take responsibility. The extensive support provided by AusAID through the LJSP and more recently the PALJP has also been important, including one full-time advisor, funding for office renovations and support on management issues such as human resources, finances, and information technology. Progress by other sectoral agencies which benefit from Australian support has 
created a degree of momentum in the law and justice sector and even competition among the different agencies to improve the performance of their agencies. Pressure from politicians and the public to reduce the backlog of cases before the courts has been yet another incentive for change. All these factors have come together in the OPS

\section{Notes}

1 http://wordnetweb.princeton.edu/perl/webwn (accessed 28 January 2010).

2 Legitimacy is a perception that the actions of an entity or system are desirable, proper or appropriate within socially accepted norms, values, beliefs and definitions.

3 Resilience refers to the ability of an entity to deal with shocks and disruptions without changing its fundamental nature or its ability to create value.

4 Relevance refers to how pertinent, connected, or applicable something is to something else.

\section{References}

Baser, Heather (2009a) An Experimental Approach to Monitoring Capacity and Capacity Development: The Case of the Office of the Public Solicitor, Port Moresby: Cardno Acil

Baser, Heather (2009b) An Experimental Approach to Monitoring Capacity and Capacity Development: An Overview of the Findings and an Assessment of the Framework, Port Moresby: Cardno Acil

Baser, H. and Morgan, P. (2008) Capacity, Change and Performance, Maastricht: European Centre for Development Policy Management (ECDPM)

Blank, L. (2008) Rapid Youth Assessment in Port Moresby, Papua New Guinea, Port Moresby: World Bank

Dinnen, Sinclair (2004) Abstract for Building Bridges: Law and Justice Reform in Papua New Guinea, Discussion Paper 02/2, Canberra: to create a virtuous cycle: a complex of events or activities that reinforce each other through feedback loops. The challenge will be to continually develop the internal capabilities of the OPS to support this cycle and to strengthen the legitimacy of the organisation.

An organisation is relevant, for example, if its activities address a purpose, issue or problem recognised as important by the society.

5 The term used by staff of the OPS.

6 This diagram is adapted from a presentation by Deborah Rhodes of Melbourne, Australia to a capacity development showcase organised by Patricia Lyon in AusAID in Canberra in November 2008.

7 All figures from Law and Justice Sector (2009: 5).

Australian National University, State, Society and Governance in Melanesia Project

Dinnen, Sinclair (2003) Building Bridges: Law and Justice Reform in Papua New Guinea, Discussion Paper 01/3, Canberra: Australian National University, State, Society and Governance in Melanesia Project

Law and Justice Sector (2009) Annual Performance Report 2008, Goal 2, Port Moresby: Law and Justice Sector Secretariat

Law and Justice Sector (2006) Sector Strategic Framework, Port Moresby: Law and Justice Sector Secretariat, www.lawandjustice.gov.pg/ resources/documents/SSF_w-_PMF.pdf (accessed 29 January 2010)

Office of the Legislative Council (1976) Constitution of the Independent State of Papua New Guinea, www.paclii.org/pg/legis/consol_act/ cotisopng534/ (accessed 29 January 2010) 